\title{
Spatio - Temporal Analysis of Land Use / Land Cover Changes in Cheha District, South - Central Ethiopia
}

\author{
Solomon Kebebew ${ }^{1 *} \quad$ Bobe Bedadi $^{1} \quad$ Teklu Erkossa $^{2} \quad$ Fantaw Yimer $^{3} \quad$ Lemma Wogi $^{4}$ \\ $1 *$ College of Agriculture and Natural Resource, Department of Natural Resource Management, Wolkite \\ University, P.O. Box 07, Wolkite, Ethiopia \\ 1,4School of Natural Resources Management and Environment Sciences, Haramaya University, \\ P. O. Box 138, Dire Dawa, Ethiopia \\ 2.Internationale Zusammenarbeit (GIZ) GmbH, Ethiopia \\ 3.Wondo Genet College of Forestry and Natural Resources, Hawassa University, P.O. Box 128, Shashemene, \\ Ethiopia
}

\begin{abstract}
Land use and land cover (LULC) dynamics pose negative impacts to land resources. Evaluation of the rate and extent of change is, therefore, indispensable for managing the environment and its implications on sustainable land resource management of the study area. The study was aimed to analyze the spatial and temporal dynamics of LULC of Cheha district during 1973 to 2017 periods and assess the implications in LULC changes. All acquired imageries of the study area were geo-referenced and re-projected. A supervised classification with maximum likelihood technique was employed to extract multispectral satellite data from Landsat using GIS and ERDAS imagine software. The Landsat imageries were monitored for (1973, 1987, 2000 and 2017) period. Seven thematic maps of land classes were identified and generated using remote sensing techniques and field verification. The study results showed the areal extent of shrub, bare and forest lands decreased by $(29.6 \%)$, (19.4\%) and (7.5\%), respectively during 1973 to 1987 interval. However, built-up area was increased considerably by $(57.3 \%)$ and agriculture land $(18.9 \%)$ in the same span. The area coverage of built-up, agriculture and forest lands, during the entire study period (1973 - 2017) increased by $(67.1 \%),(31.6 \%)$ and (59.7\%), respectively. Conversely, the respective yearly change of grazing, shrub and bare land classes over the study period was (-194.4 ha), (-114.7 ha) and (-60.3 ha). The LULC dynamics pretended a serious threat to land resources in the study area over the past 44 years. Therefore, better understanding of its underlying causes and associated driving forces could support in developing sustainable land resource management in the area.
\end{abstract}

Keywords: land use/land cover change, Image classification, GIS, remote sensing

DOI: $10.7176 / \mathrm{JEES} / 11-7-01$

Publication date:July $31^{\text {st }} 2021$

\section{INTRODUCTION}

Land use and land cover (LULC) change is dynamic, widespread and accelerating process mainly driven by natural phenomena and anthropogenic activities (Ahmad, 2012). LULC changes as the core of coupled humanenvironment systems have become a potential field in the study of global and local environmental change which is increasingly considered as an important component of environmental change and sustainable development studies (Liu et al., 2010). LULC dynamics are central issue requiring thorough scientific investigation for sustainable land use planning and development Lambin (2003) and representing a vibrant and dynamic area of research. The human induced activities and growth, socio-economic factors, deterioration of vegetation cover, and agricultural activities might influence changes in land use and land cover of an environment (Alemayehu and Arnalds, 2011).

On the other hand, the changes and the continuous use of lands for cultivation purposes resulted in a disastrous loss of soil nutrients, particularly in the highlands where erosion is more severe Kindu et al. (2016) due to variations in slope gradients. The study on change detection that involves applying multi-temporal remote sensing information to analyze the historical effects of an occurrence quantitatively and help in determining the changes associated with LULC properties with reference to the multi-temporal datasets (Amna et al., 2015).

Various studies (Woldeamlak Bewket, 2002; Asmamaw, 2013; Sabiela Fekad et al., 2020) have been conducted in many parts of Ethiopia regarding the change analysis of land-use types through different methods that are important to develop effective management strategies for land resources. Kiros (2008) reported increased agricultural land areas at the cost of natural vegetation like woodland and shrub land over the past 41 years. In the highlands of Ethiopia, LULC changes have increased the surface run-off and stream flow leading to loss of wetlands and dying of lakes (Alemayehu and Arnalds, 2011). Tekle and Hedlund (2000) showed a decrease in the coverage of shrub lands and forests, but areas under cultivation LULC changes have also been significant in Southern Ethiopia.

Tools such as remote sensing and geographic positioning system provide a reliable source of data for assessing and monitoring spatial and temporal land use and land cover changes. A combined use of such 
technology can be invaluable to address a wide variety of resource management problems (Tekle and Hedlund, 2000). On the other hand, producing maps land use and land cover is a powerful tool to compare the changes of an area over time.

In the study area, large scale expansion of eucalyptus plantation and cultivations of crops that could able to change the farming system of the area have been posing land degradation and loss of soil productivity. As a result of these land resource degradation processes, persistent negative changes are taking place in socioeconomic of the community and the environment. LULC change is increasingly recognized as an important driver of environmental change on all spatial and temporal scales. Consequently, the assessment of land use patterns and their changes at the study area is crucial for better understanding of driving forces for better understanding of driving forces and management of land resources.

Therefore, study of LULC dynamics for the past 44 years in the area was found to be basic in identifying the underlying causes to changes and its implications for sustainable land resources management. On top of this, proper understanding of the variations occurring in the area overtime and the pattern of land use dynamics could support decision-making for appropriate land management strategies. In addition, it is necessary to tackle the impacts of LULC through appropriate management practices, land use planning and implementation. The objective of this study is, therefore, to analyze the spatial and temporal dynamics of LULC of Cheha district during 1973 to 2017 periods and investigate the major drivers governing the observed changes.

\section{MATERIALS AND METHODS}

\subsection{Description of the Study Area}

The study area was conducted at Cheha district, Guraghe Zone, Southern Nations, Nationalities, and Peoples' Regional State (SNNPRS), Ethiopia. It is located at coordinates between $08^{\circ} 05^{\prime} 30^{\prime \prime} \mathrm{N}$ and $08^{\circ} 06^{\prime} 0^{\prime \prime} \mathrm{N}$ latitude and $37^{\circ} 58^{\prime} 30^{\prime \prime} \mathrm{E}$ and $37^{\circ} 59^{\prime} 0^{\prime \prime} \mathrm{E}$ longitude with altitude ranging from 1055 to $2816 \mathrm{~m}$ above sea level and covering about 57528.0 ha of land area (Figure 1). The area has three agro-ecological zones of Dega, Wainadega and Kolla CHWAOR (2016) with an average land holding of ( 0.5 ha per household head).

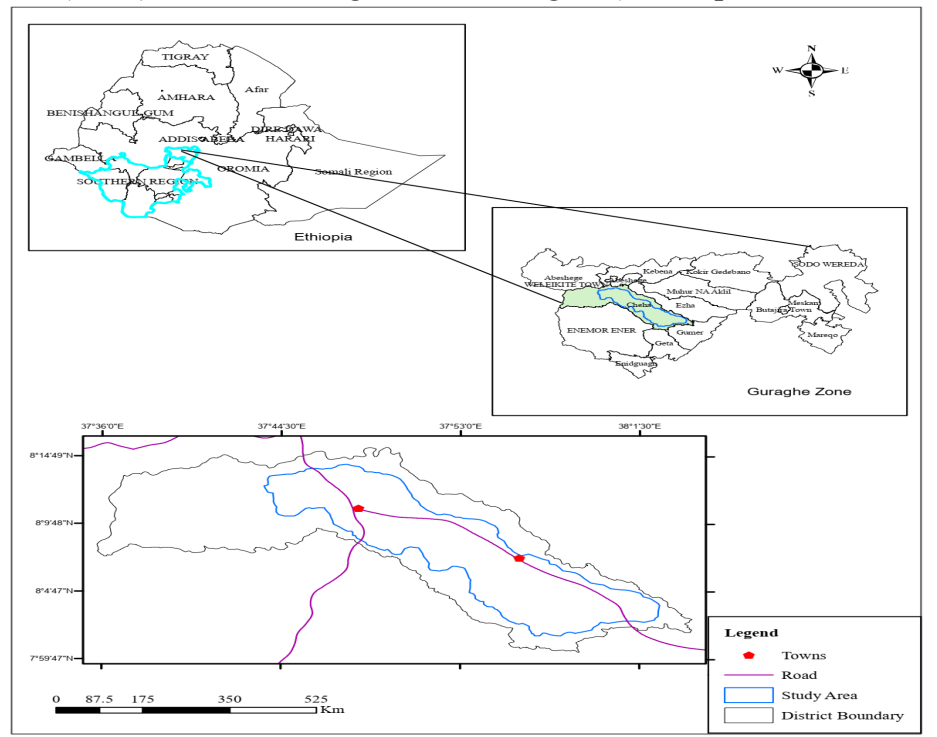

Figure 1. Map of the Study area.

The study area is characterized by monomodal with a mean annual rainfall of $1143.33 \mathrm{~mm}$ and the mean annual minimum and maximum temperatures of the area are 11.29 and $25.45^{\circ} \mathrm{C}$, respectively (Figure 2). 


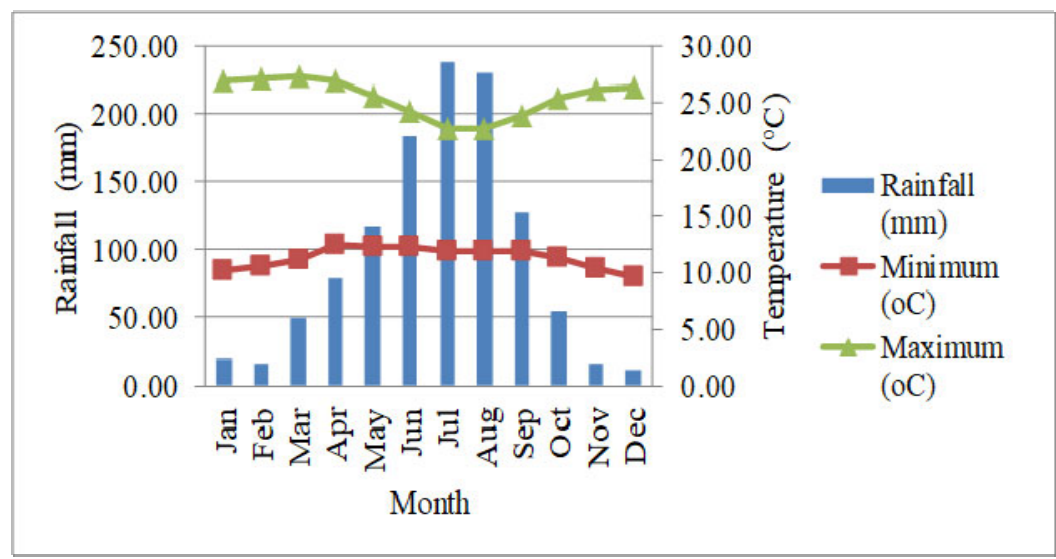

Figure 2. Mean monthly rainfall, maximum and minimum temperatures (1995-2015)

The area usually is drained by many rivers including the Megecha, Gotam, Gogab are the main rivers that flows into the area and Wabe, Wunke and Kinke which are shading to the Omo-Gibe basin.

Table 1. Descriptions of studied land use land cover class types in the study area.

\begin{tabular}{|c|c|}
\hline LULC Classes & Description \\
\hline Forest land & $\begin{array}{l}\text { Areas covered with forest trees forming closed or nearly closed canopies forest and } \\
\text { plantation forest land. }\end{array}$ \\
\hline Grazing land & Areas of land where small grasses are the predominant usually used for grazing. \\
\hline Shrub land & Areas covered with small trees, short shrubs and thorny bushes with little useful wood. \\
\hline Agriculture land & $\begin{array}{l}\text { Areas allocated to rainfed and irrigated agriculture land (both seasonal and perennial) } \\
\text { crops with enset and/or khat fields. }\end{array}$ \\
\hline Built-up & $\begin{array}{l}\text { Areas covered with buildings in rural and urban that includes commercial, residential, } \\
\text { industrial, and transportation infrastructures. }\end{array}$ \\
\hline Bare land & $\begin{array}{l}\text { An open land cover or exposed land surface areas with degraded (temporary or } \\
\text { permanent) bare soil patches without vegetation cover. }\end{array}$ \\
\hline Water body & Area covered with rivers and streams \\
\hline
\end{tabular}

\subsection{Data Sources and Preparation}

In the present study, LULC changes were monitored within the time span of (1973-2017) acquired at the same dry season. The preliminary survey and questionnaires were used to collect demographic and socio-economic data to identify and assess the underlying factors of LULC changes. A total of 135 key informants were purposively sampled for interview. Besides, group discussion was used to generate information regarding overall trends of changes in LULC, historic and present natural resources management. The Landsat imageries TM and ETM+ (with a resolution of $30 \times 30$ m pixel) were acquired for (1973, 1987, 2000 and 2017) periods including the black and white aerial photos for 1973 from Ethiopian Mapping Authority (EMA).

Table 2. The Acquisition Dates, Sensor, Path/Row and Resolution of Landsat Images.

\begin{tabular}{|c|c|c|c|c|}
\hline No. & Sensor & Path/Row & Spatial Resolution & Acquisition Date \\
\hline 1 & Landsat MSS & $169 / 54$ & $57 \times 57 \mathrm{~m}$ & 1973 \\
\hline 2 & Landsat TM & $169 / 54$ & $30 \times 30 \mathrm{~m}$ & 1987 \\
\hline 3 & Landsat TM & $169 / 54$ & $30 \times 30 \mathrm{~m}$ & 2000 \\
\hline 4 & Landsat ETM+ & $169 / 54$ & $30 \times 30 \mathrm{~m}$ & 2017 \\
\hline
\end{tabular}

$\mathrm{ETM}^{+}=$Enhancing thematic mapper plus; MSS = Multispectral Scanner; $\mathrm{TM}=$ Thematic mapper.

\subsection{Image Processing and Analysis}

The LULC change analysis were performed after all images were stacked, geo-referenced, re-projected to Universal Transverse Mercator co-ordination system (WGS 1984, zone $37 \mathrm{~N}$ ), and the Area of Interest (AOI) was extracted from images using subset tools and fit to the boundary of study area with spatial grid of $30 \mathrm{~m}$ resolution using the nearest neighbor technique. The LULC analysis was carried out following the maximum likelihood (MLH) supervised pattern of classification using band combination of (4 32 ) color composite images (Butt et al. (2012) using combinations of software ERDAS IMAGINE 14 and ArcGIS. The percent and rate of change were computed using equations 1 and 2, respectively. The annual rate of change between those years was calculated by dividing the change of the given LULC type by the number of years between the two intervals. 


$$
\begin{aligned}
& \text { Percent of change }=\left(\frac{X-Y}{Y}\right) * 100 \\
& \text { Rate of change (ha per year) }=\left(\frac{\mathrm{X}-\mathrm{Y}}{\mathrm{Z}}\right)
\end{aligned}
$$

where, $X$ is area of LULC (ha) in time final year, $Y$ is area of LULC (ha) in time initial, $Z$ is time interval between $X$ and $Y$ in years.

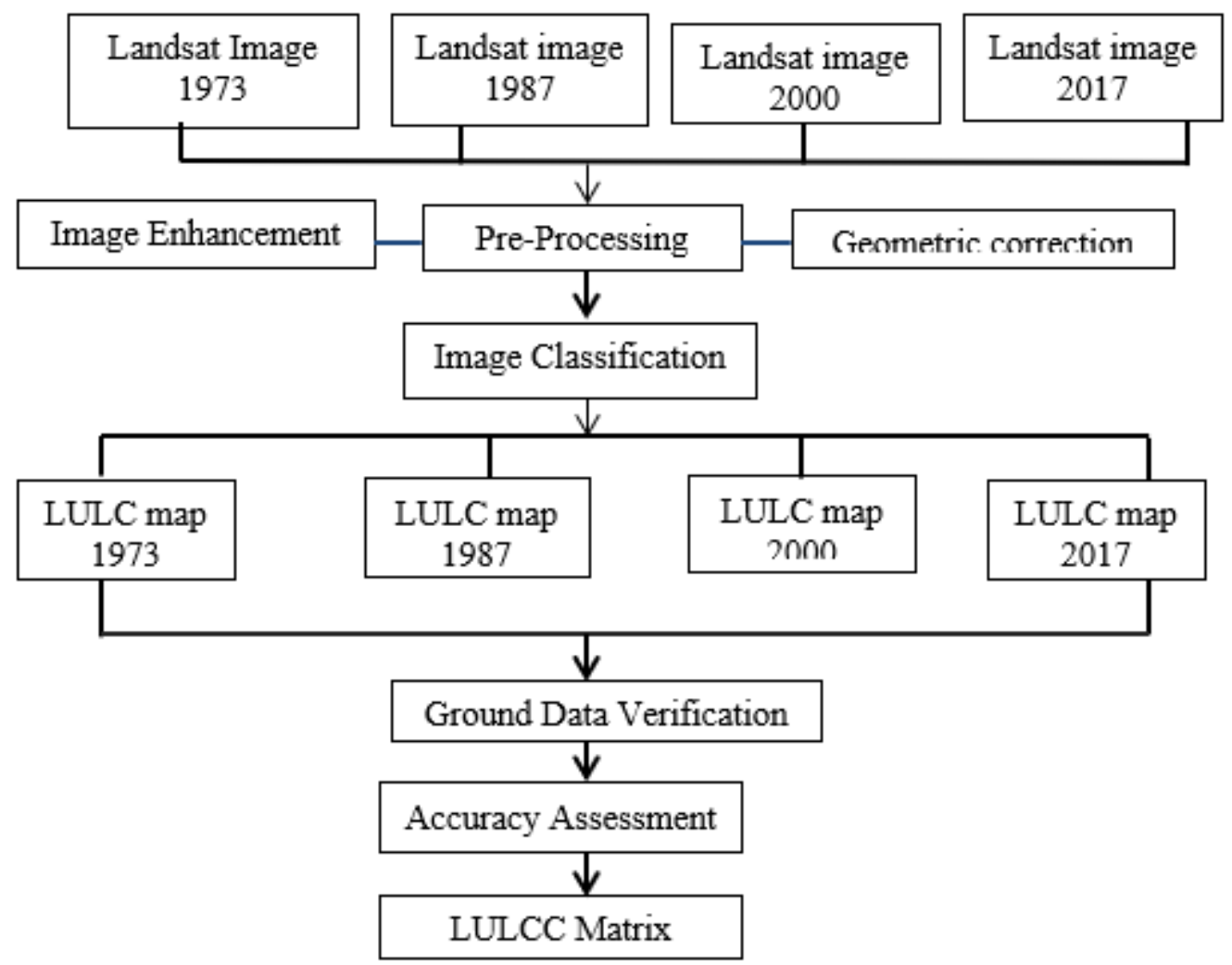

Figure 3. Schematic illustration of analysis of land use and land cover changes.

\subsection{Accuracy Assessment for Image Classification}

The accuracy assessment was performed using both remotely sensed and field data, verified by ground control points (GCPs) collected during field visits. The classified LULC thematic map classes were cross-checked with 1150 GCPs and complemented with Google Earth besides the author's previous and current knowledge of the object scene in the study area. The user's, producer's, overall classification accuracy Congalton and Green (1999) and kappa coefficient (k) Lillesand et al. (2004) were calculated from generated error matrices. Overall accuracy was computed by dividing the number of pixels correctly classified for total number of pixels.

$$
\text { Kappa } \quad(\mathrm{K})=\frac{N * \sum_{i=1}^{K} X_{a b}-\sum_{i=1}^{K}\left(X_{a} * X_{b}\right)}{\mathrm{N}^{\wedge} 2-\sum_{i=1}^{K}\left(X_{a}-X_{b}\right)}
$$

Where, $\mathrm{K}=$ Kappa coefficient; $\mathrm{N}$ is sample size; $\sum_{i=1}^{K} X_{a b}$ is observed accuracy and $\sum_{i=1}^{K}\left(X_{a} * X_{b}\right)$ is chance accuracy.

\section{RESULTS AND DISCUSSION}

\subsection{Land Use and Land Cover (LULC) Change Analysis}

Results showed marked changes in LULC was observed within a time span of 44 years $(1973$ - 2017). The agriculture land area in 1973 (the initial state) occupied (28.3\%) of the total area, followed by grazing land (20.9\%), shrub land (18.5\%), bare land (16.5\%), water body (5.8\%), forest cover (5.6\%) and built up (4.5\%) 
(Table 3) and (Figure 4 and 5). The land areas covered by bare and grazing lands declined since 1987, this could be an immense plantation of eucalyptus trees in the area. Results revealed that an appreciable increase in the area of built up, agriculture land and forest land during the period of 1973 - 2017 at the expense of reduction in shrub and grazing land areas. The category of agricultural area showed consistent increase since 1987 from (33.6\%) to $(39.4 \%)$ in 2000 while (41.4\%) in 2017. Barana Babiso et al. (2016) also reported an increased areal coverage of cultivated land. Similarly, results showed that forest area coverage markedly increased over the past 44 years by $(59.7 \%)$ at the expense of decreased grazing land and bare land. The area under forest class constituted only $(5.6 \%)$ of the total in 1973 and increased to (13.8\%) in 2017. Alemayehu and Arnalds, (2011) also found a drastic decline in forest cover and a corresponding increase in cultivated land in between 1960s and 1980s in the South-Central Ethiopia highlands.

The classified map of 1987 showed that grazing land covered the largest $(24.0 \%)$ portion of the area, but consistently diminished to $(6.0 \%)$ in 2017 . This is because most of LULC classes were reduced and changed to agriculture, built up and forest classes. Likewise, the shrub land area occupied $(18.5 \%)$ in 1973 ; however it deceased significantly and consistently to $(9.7 \%)$ in 2017 . A similar trend observed in bare land areas that a profound decrease in 2000 this land use occupied an area of 5885.89 ha (10.2\%) as against 9461.0 ha (16.5\%) in 1973. Results showed that built up area has been shown consistent increase since 1973.

Table 3. Land Use and Land Cover Classes and Areal Coverage (1973-2017).

\begin{tabular}{lcccccccc}
\hline & \multicolumn{7}{c}{ Area Coverage } \\
\cline { 2 - 8 } & 1973 & \multicolumn{1}{c}{1987} & & 2000 & & 2017 \\
\hline LULC Classes & $(\mathrm{ha})$ & $(\%)$ & $(\mathrm{ha})$ & $(\%)$ & $(\mathrm{ha})$ & $(\%)$ & $(\mathrm{ha})$ & $(\%)$ \\
\hline Agriculture & 16272.1 & 28.3 & 19344.5 & 33.6 & 22672.4 & 39.4 & 23790.7 & 41.4 \\
Forest & 3202.2 & 5.6 & 2962.2 & 5.1 & 9000.1 & 15.6 & 7938.0 & 13.8 \\
Grazing & 12030.6 & 20.9 & 13812.8 & 24.0 & 6197.0 & 10.8 & 3478.7 & 6.0 \\
Shrub & 10650.2 & 18.5 & 7500.7 & 13.0 & 6990.9 & 12.2 & 5603.0 & 9.7 \\
Bare & 9461.0 & 16.5 & 7625.2 & 13.3 & 5885.9 & 10.2 & 6806.9 & 11.8 \\
Built up & 2565.3 & 4.5 & 4035.7 & 7.0 & 5273.7 & 9.2 & 7791.3 & 13.5 \\
Water body & 3346.6 & 5.8 & 2246.9 & 3.9 & 1508.1 & 2.6 & 2119.4 & 3.7 \\
\hline Total area & 57528.0 & & 57528.0 & & 57528.0 & & 57528.0 & \\
\hline
\end{tabular}

LULC $=$ Land Use and Land Cover

The areal extent coverage was (4.5\%) in 1973 and slight increment in 1987 and 2000, but tremendously increased in 2017 (Figure 4, 5 and Table 3). Water body covered (5.8\%) of the area in 1973 that appears to have decreased at a rate of (32.9\%) during (1973-1987). It changes at the rate of (27.9 ha) per year during the entire period from the total cover. The dynamics might be attributed to the use of main rivers and streams (Wunke, Megecha, Gotam and Gogab) for irrigation in turn increased the agriculture land area while diminishing area under water body.

\subsection{Trend and Rate of Land Use Land Cover Change}

The LULC maps illustrated larger area was primarily occupied by agriculture land in 2017 followed by forest cover. The patter of changes in agriculture land area showed a consistent trend over the study period. The area increased by (17.20\%) in between 1987 and 2000 with (256.0 ha) per year and (4.9\%) in 2000 and 2017 interval. The changes might be due to agriculture activities like enset crop (main food source); cultivation of crops is mainly practiced in the entire study area. In between 1987 and 2000, major losses were observed in grazing $(55.1 \%)$ and bare $(22.8 \%)$ land covers. This is because agriculture land was expanded at the expense of these two land cover at higher annual growth rate. The cultivated land showed an increased trend Asmamaw et al. (2011) at the expense of grassland. The area under forests decreased by (7.5\%) between 1973 and 1987 (-17.1 ha) per year. The pattern of changes showed an irregular trend over the period under study. The rate at which such change occurred was very high from 1987 to 2000 and then declined significantly in between 2000 and 2017 . The decline in forest cover area was due to human activities in forest wood cutting for high market value and also the rigorous use of forest trees for new house construction.

Similar results showed an improvement in LULC change was observed in between (1980s-2000s) in terms of vegetation cover in south-central Ethiopian highlands Alemayehu and Arnalds, (2011) mainly attributed to reafforestation programmes, predominantly eucalyptus. However, it was retrieved and increased by $(203.83 \%)$ between 1987 and 2000 (464.5 ha) per year, but in between 2000 and 2017, it again decreased by 11.80\% (-62.5 ha) per year. On the other hand, grazing land cover reduced by (55.1\%) from 1987 to 2000, and further shrank by (43.9\%) in between 2000 and 2017 . The initial increase $(14.8 \%)$ in the areal extent of grazing land between 1973 and 1987 is probably associated to a controlled norm established by local community toward serving a communal grazing. Furthermore, the decrease was mainly due to open grazing land transformed to barren roads (Joforo: parts of grazing land area located between clustered settlements used as communal grazing and barren roads), rural settlements in cluster and small portion changed to plantation of eucalyptus trees for income of local 
communities.

The areal extent of shrub land decreased by (29.6\%) in between 1973 and 1987, and then continue to decrease, with an overall reduction of (90.1\%) (Table 4). The pattern of changes in shrub land cover followed a downward trend. This could be attributed to an increase demand for fuel wood and expansion of eucalyptus tree plantation. Similar results by Gashaw et al. (2017) reported as shrub land decreased at higher rate during the study period in Andassa watershed.

\section{Maps of LULC types of Cheha district in between 1973-2017}

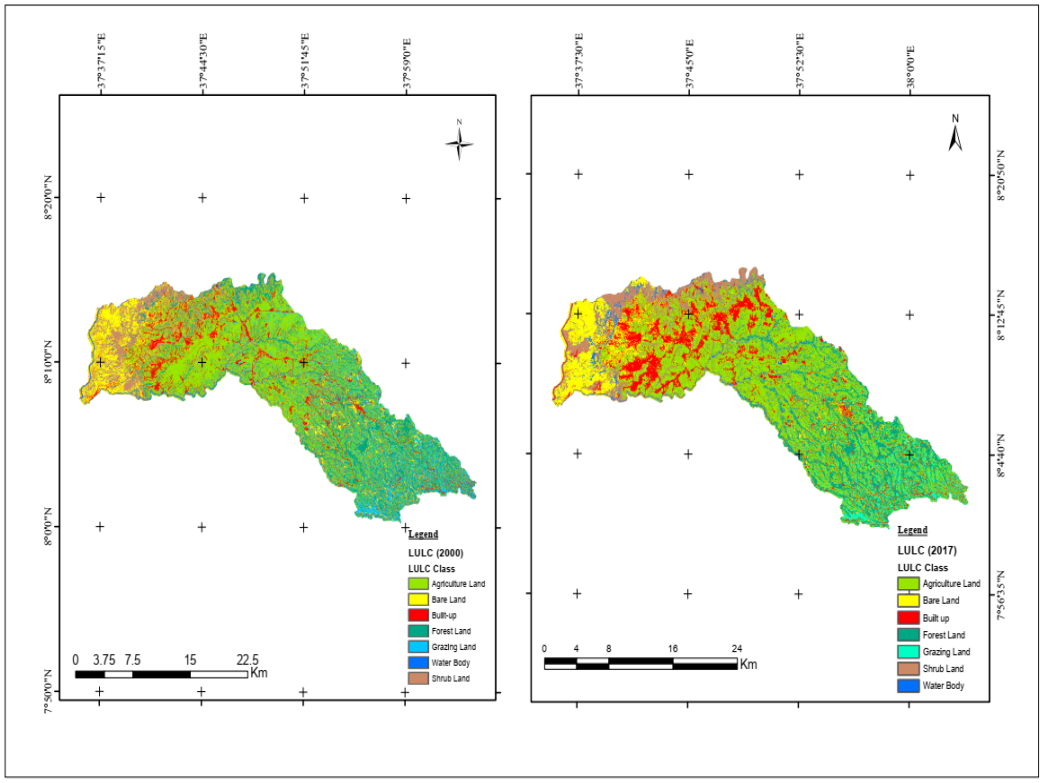

Figure 4. Maps of LULC types of Cheha district (1973 and 1987).

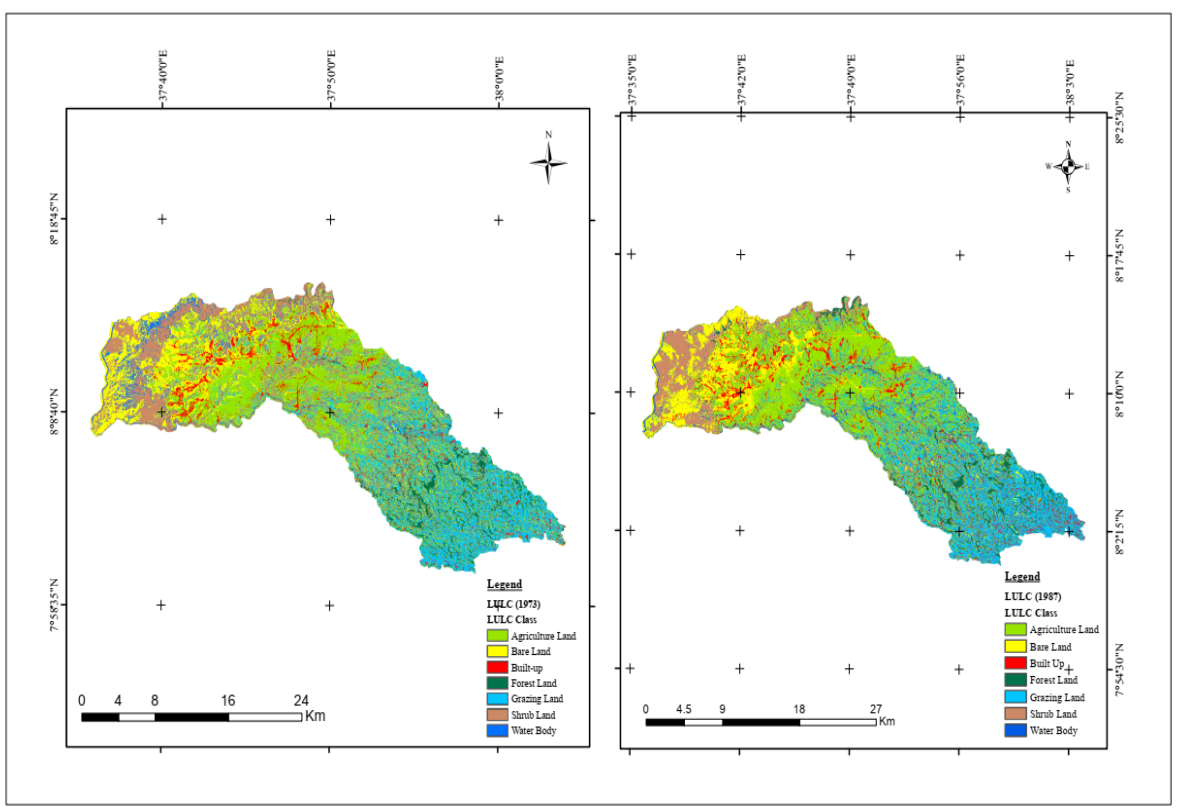

Figure 5. Maps of LULC types of Cheha district (2000 and 2017).

The area of bare land deceased on a steady basis by (-19.4\%) during 1973 to 1987 and $(-22.8 \%)$ in between 1987 and 2000 period. However, the pattern of changes indicated that area cover increased by $(15.6 \%)$ in between 2000 and 2017. Such pattern of change is a quite usual in small-scale subsistence farming areas where land abandoned Tolessa et al. (2016) practices is common due to soil fertility problem. Between the year 1987 and 2000 the annual rate of change in bare land decreased by (133.8 ha) per year, but increased by ( $54.2 \mathrm{ha})$ per year in between 2000 and 2017. This increment was due to rapid destruction of vegetation and cutting of eucalyptus trees by the local communities for market and construction in the area that rendered the area to exposed rocks/soils. Built up area, immensely increased by more than (57.3\%) in (1973 - 1987) and showed a 
persistent trend of rising at the rate of (118.8 ha) per year in the analysis period. Similar result by Gashaw et al. (2017) showed that increased area of built-up by (562.8\%) during 2000 - 2015 in the studied watershed.

Table 4. Rate of LULC Change between 1973-1987, 1987-2000 and 2000-2017.

\begin{tabular}{|c|c|c|c|c|c|c|c|c|c|c|c|c|}
\hline \multirow[t]{2}{*}{ LULC Classes } & \multicolumn{3}{|c|}{$1973-1987$} & \multicolumn{3}{|c|}{$1987-2000$} & \multicolumn{3}{|c|}{$2000-2017$} & \multicolumn{3}{|c|}{$1973-2017$} \\
\hline & RAC & $(\%)$ & RACY & RAC & $(\%)$ & RACY & RAC & $(\%)$ & RACY & RAC & $(\%)$ & RACY \\
\hline Agriculture & 3072.4 & 18.9 & 219.5 & 3327.9 & 17.2 & 256.0 & 1118.3 & 4.9 & 65.8 & 7518.6 & 31.6 & 170.9 \\
\hline Forest & -240.0 & -7.5 & -17.1 & 6037.9 & 203.8 & 464.5 & -1062.1 & -11.8 & -62.5 & 4735.8 & 59.7 & 107.6 \\
\hline Grazing & 1782.2 & 14.8 & 127.3 & -7615.8 & -55.1 & -585.8 & -2718.3 & -43.9 & -159.9 & -8551.9 & -245.8 & -194.4 \\
\hline Shrub & -3149.5 & -29.6 & -225.0 & -509.8 & -6.8 & -39.2 & -1387.8 & -19.9 & -81.6 & -5047.2 & -90.1 & -114.7 \\
\hline Bare & -1835.8 & -19.4 & -131.1 & -1739.3 & -22.8 & -133.8 & 921.0 & 15.6 & 54.2 & -2654.1 & -39.0 & -60.3 \\
\hline Built-up & 1470.4 & 57.3 & 105.0 & 1238.0 & 30.7 & 95.2 & 2517.6 & 47.7 & 148.1 & 5226.0 & 67.1 & 118.8 \\
\hline Water body & -1099.7 & -32.9 & -78.5 & -738.8 & -32.9 & -56.8 & 611.3 & 40.5 & 36.0 & -1227.2 & -57.9 & -27.9 \\
\hline
\end{tabular}

LULC $=$ Land Use and Land Cover; RAC = Rate of Area Change; RACY= Rate of Change per year (ha)

The increased built-up area (47.7\%) in between 2000 and 2017 with a yearly increment of (148.1 ha) that corresponds to the population growth and establishment towards towns. The percentage decrease in grazing cover area was more rapid as compared to in bare land and shrub land areas. The grazing land cover decreased by (55.1\%) during 1987-2000 period as against (43.9\%) from 2000 to 2017 time period. The yearly change in grazing land cover was $(-194.4)$ ha with the overall change of $(-43.9 \%)$ in the entire study period. This rate is follow the trend of built up area during the corresponding period thus; more grazing land could be transformed to built-up areas.

\subsection{Accuracy assessment of LULC maps}

The overall classification accuracy of the LULC derived from Landsat TM scenes was (89.65\%) and the overall kappa coefficient of (0.753) for LULC maps (Table 5). Therefore, result of accuracy level is in agreement with the standard accuracy (85-90\%) for LULC mapping studies as recommended by (Anderson et al., 1976). In addition, the kappa coefficient value of this classification, on the other hand, was greater than 0.7 suggests the classification efficiency was a very good agreement Monserud (2002), in terms of kappa coefficient ranges.

Table 5. Accuracy Assessment matrix for Land Use and Land Cover

\begin{tabular}{lcccccccccc}
\hline Land use types & Agriculture & Forest & Grazing & Shrub & Built-up & Bare & Water & Total Row & CE & UA \\
\hline Agriculture & $\mathbf{1 7 3}$ & 0 & 6 & 0 & 6 & 5 & 0 & 190 & 8.95 & 91.05 \\
Forest & 0 & $\mathbf{1 3 1}$ & 0 & 10 & 0 & 0 & 4 & 145 & 9.66 & 90.34 \\
Grazing & 3 & 0 & $\mathbf{1 4 6}$ & 3 & 6 & 8 & 0 & 166 & 12.05 & 87.95 \\
Shrub & 6 & 8 & 0 & $\mathbf{1 5 3}$ & 0 & 0 & 8 & 175 & 12.57 & 87.43 \\
Built-up & 9 & 0 & 3 & 0 & $\mathbf{1 3 9}$ & 7 & 0 & 158 & 12.03 & 87.97 \\
Bare & 3 & 0 & 5 & 0 & 11 & $\mathbf{1 4 4}$ & 0 & 163 & 11.66 & 88.34 \\
Water & 0 & 2 & 0 & 6 & 0 & 0 & $\mathbf{1 4 5}$ & 153 & 5.23 & 94.77 \\
\hline Total Column & 194 & 141 & 160 & 172 & 162 & 164 & 157 & $\mathbf{1 1 5 0}$ & & \\
\multicolumn{1}{c}{ OE } & 10.82 & 7.09 & 8.75 & 11.05 & 14.20 & 12.20 & 7.64 & & & \\
\multicolumn{1}{c}{ PA } & 89.18 & 92.91 & 91.25 & 88.95 & 85.80 & 87.80 & 92.36 & & &
\end{tabular}

$\mathrm{PA}=$ Producer accuracy $(\mathrm{PA}) ; \mathrm{UA}=$ User accuracy $(\mathrm{UA}) ; \mathrm{OE}=$ Omission error and $\mathrm{CE}=$ Commission error

\subsection{Major Driving Forces of LULC Changes}

There are several interacting factors directly or/and indirectly that have caused considerable changes in LULC changes of study area. The major forces such as population pressure, vegetation loss, and slope gradient were identified among main natural and anthropogenic driving forces primarily leading the changes in the study area. The growing population is one of the most critical drivers of the observed land cover dynamics due to the livelihood of rural population dependence on agriculture. According to CSA (1994) census report the total population of the study area was 115,864 and in 2007 increased to 115,951 CSA (2008) this showed slight increase $(0.08 \%)$ in total population over 13 years. However, the urban population increased by $(143.49 \%)$ in 2007 contributed a higher area coverage by built-up. Moreover, the increase in population of urban could certainly the primary driver of LULC changes in the studied area which was manifested largely through the expansion of built-up area at the expense of shrub land and grazing land covers. Most studies pinpoint 
population pressure as one of the major drivers of LULC change (Nuahsenay et al., 2015). The second driving forces were the strong influence of expanding eucalyptus plantation and associated activities on fragmented lands (0.5 ha per household) which were more propitious and concerning since $1980 \mathrm{~s}$. Results showed that out of the 135 key informants interviewed; about (79.26\%) key informants responded that their eucalyptus tree plantations area coverage have been expanded pointedly in the past 20-30 years at the expense of grazing land and agriculture land areas to ensure annual income for the household.

On the other hand, only (20.74\%) of the farmers expanded their agriculture to produce crops for commercial purpose. In general, intensive plantation of eucalyptus clearly understood in the past 30 years with a remarkable rise in vegetation cover. During field visits, key informants pointed that reduction of land productivity was also an indicator for seeking new additional land area for plantations and reflected as associated driving force to LULC changes. Such remarkable land degradation in the study area was considered to be the third driving forces. The geographic and topographic relationship of changes in LULC were also other main problems associated with land degradation in the steep slope areas that have been found to experience soil degradation leading to associated sever soil erosion. Loss of land productivity coupled with associated sever soil erosion problem might be considered other underlying local driving factors in the study area.

\section{CONCLUSION}

The present study assessed the trend of LULC changes and spatial distribution of different land cover changes of Cheha district, by integrating GIS and remote sensing. Overall $(89.65 \%)$ accuracy of the LULC maps indicated that the integration of supervised classification of satellite imagery with visual interpretation is an effective method in detecting changes in LULC of an area. The remarkable expansion of Eucalyptus plantation and population pressure with limited income diversity is the major driving forces for the changes of land use land cover. A considerable increase in built-up (57.3\%) and agriculture (18.9\%) land area in between 1973 to 1987 was observed. The continually demand for house constriction material and economic value of Eucalyptus tree over agriculture crops increased the forest land covers to 9000.10 ha at an average rate of (5.6\% per year) at the end of 2000. The implications of these changes suggest that the LULC have skewed to the extensive conversion of areas of grazing and shrub land to forest land and built-up areas. In general, LULC changes mainly associated with the degradation of land resources, expansion of urban sprawl, loss of forest as well as agricultural productivity. Therefore, the need for appropriate intervention in land policy formulation and its implementation, land use planning and management practices are crucial for the rational use of land resources and curtail the degradation of environmental resources.

\section{ACKNOWLEDGEMENTS}

The authors are thankful to Ministry of Education and Wolkite University for facilitating the study and for their financial supports for the research work.

\section{REFERENCES}

Ahmad, F. (2012). Detection of change in vegetation cover using multi-spectral and multi-temporal information for District Sargodha, Pakistan. Sociedade Natureza, (24): 557-572.

Alemayehu, M. and Arnalds O. (2011). Synthesis of Research on Land Use and Land Cover Dynamics in the Ethiopian Highlands. Geophysical Research, 112: 1-39.

Amna, B., Rabia, S., Sheikh, S.A. and Neelam, A. (2015). Land use change mapping and analysis using Remote Sensing and GIS: A case study of Simly watershed, Islamabad, Pakistan, The Egyptian Journal of Remote Sensing and Space Sciences, (18): 251259.

Anderson, J.R, Hardy, E.E., Roach, J.T. and Witmer, R.E. (1976). A land use and land cover classification system for use with remote sensor data. Us geological survey professional paper, 964. A revision of the land use classification system as presented in U.S. Geological survey circular 671 Washington, USA, Government Printing Office.

Asmamaw, L., Mohamed, A. and Lulseged, T. (2011). Land use/cover dynamics and their effects in the Gerado catchment, northeastern Ethiopia. International Journal Environment, (68):883-900.

Barana B., Senbetie T. and Aklilu B. (2016). Land use/Land Cover Dynamics and its Implication on Sustainable Land Management in Wallecha Watershed, Southern Ethiopia, Global Journal of Science Frontier Research: Environment and Earth Science, 16(4): 49-63.

Butt, M.J., Waqas, A., Iqbal, M.F., Muhammad, G., and Lodhi, M.A.K. (2012). Assessment of urban sprawl of Islamabad metropolitan area using multi-sensor and multi-temporal satellite data. Arabian Journal for Science and Engineering, (37): 101-114.

Central Statistical Agency (CSA). (2008). Agricultural Sample Survey. Report on Area and Production. SNNP Region. Version 1.1. 
Central Statistics Agency (CSA). (1995). The 1994 Population and Housing Census of Ethiopia. Federal Democratic Republic of Ethiopia Office of Population and Housing Census Commission central Statistical Authority, Addis Ababa, Ethiopia.

Cheha Woreda Agricultural Office Report (CHWAOR) (2016). Cheha Woreda Agriculture and Natural Resource Development Department Office Report, Guraghe zone, Ethiopia.

Congalton, R.G. and Green, K. (1999). Assessing the accuracy of remotely sensed data: Principles and practices. Lewis Publisher. Boca Raton, London, New York, Washington D.C.

Gashaw T, Tulu, T., Argaw, M., Worqlul, A.W. (2017). Evaluation and prediction of land use/land cover changes in the Andassa watershed, Blue Nile Basin, Ethiopia. Environment System Research, (6):17.

Kindu, M., Schneider, T., Teketay, D. and Knoke, T. (2016). Changes of ecosystem service values in response to land use/land cover dynamics in Munessa-Shashemene landscape of the Ethiopian highlands. Science of the Total Environment, (547):137-147.

Kiros, M. (2008). Temporal and Spatial Changes in Land Use Patterns and Biodiversity in Relation to Farm Productivity at Multiple Scales in Tigray, Ethiopia. (Unpublished).

Lambin, E. (2003). Dynamics of Land-Use and Land-Cover Change in Tropical Regions. Annual Review of Environment and Resources, (28): 205- 241.

Lillesand, T. M., Kiefer, R.W. and Chipman, J.W. (2004). Remote Sensing and Image Interpretation, $5^{\text {th }}$ Edition. John Wiley and sons, Inc., Hoboken, New Jersey.

Liu, Y.S. and Li, Y.R. (2010). Spatio-temporal coupling relationship between farmland and agricultural labor changes at county level in China. Acta Geography Sin, 65(12):1602-1612.

Nuahsenay, A., Kibebew K., Heluf, G. and Abayneh, E. "Land use/land cover dynamics at Wadla Delanta Massif, Northcentral Highlands of Ethiopia," Journal of Agriculture and Environment for International Development, vol. 6, no.9, pp. 304-320, 2015.

Sabiela, F., Kehali J., Endalkachew F., and Dessale, W. (2020). Land Use and Land Cover Dynamics and Properties of Soils under Different Land Uses in the Tejibara Watershed, Ethiopia, Scientific World Journal, $1-12$.

Tekle, K. and Hedlund, L. (2000). Land cover changes between 1958 and 1986 in Kalu District, Southern Wello, Ethiopia. Mountain Research and Development, 20(1): 42-51.

Terefe, T., Feyera, S. and Tariku, A. (2016). Land use/land cover analysis and ecosystem services valuation in the central highlands of Ethiopia, Forests, Trees and Livelihoods, DOI: 10.1080/14728028.2016.1221780.

Woldeamlak, B. (2002). Land Cover Dynamics Since the 1950s in Chemoga Watershed, Blue Nile Basin, Ethiopia. Mountain Research and Development, 22(3): 263-269. 